Vol. 5 No. 3 (2021) pp. 193 - 198

Available online at: http://jurnal.umpwr.ac.id/index.php/abdimas/index

p-ISSN: 2580-3492 e-ISSN: 2581-0162

\title{
Universitas Pertamina Starting Act (UPSTRACT) 3.0 Sebagai Edukasi Pengelolaan dan Pengolahan Limbah Padat
}

\section{Farhan Muhammad Hilmi, Abid Naufal Khairan, Muhammad Jatmoko, Mayang Ananda Rini, Yika Nabila Kharisma Putri, Safitri Puji Lestari, Nurul Aini Putri Hardi, Ari Rahman, I Wayan Koko Suryawan $\bowtie$}

\section{Universitas Pertamina}

Jl. Teuku Nyak Arief, RT.7/RW.8, Simprug, Kec. Kby. Lama, Jakarta Selatan, 12220, Indonesia

| i.suryawan@univerisitaspertamina.ac.id | DOI : https://doi.org/10.37729/abdimas.v5i3.1115 |

\begin{abstract}
Abstrak
Permasalahan sampah di lingkungan kampus menjadi salah satu tantangan. Upaya pengendalian dampak lingkungan tidak terlepas dari bagaimana cara pengolahan sampah. Himpunan Mahasiswa Teknik Lingkungan Universitas Pertamina melaksanakan rangkaian kegiatan UPSTRACT 3.0 (Universitas Pertamina Starting Act 3.0) dengan tema Solid Waste Treatment for Sustainable Cities and Communities untuk mengendalikan dampak lingkungan negatif yang mungkin terjadi. Tujuan dilakukan kegiatan ini adalah untuk kepedulian terutama warga Kampus Universitas Pertamina terhadap pengolahan sampah Rangkaian kegitan ini yaitu lomba inovasi teknologi, -pemaparan mesin pencacah plastik dan pemaparan redesain TPS, dan talk show pengolahan sampah. Tingginya tingkat inovasi lingkungan yang terukur dalam kegiatan ini berkorelasi dengan tingginya kepedulian warga kampus terhadap pencegahan pencemaran lingkungan oleh sampah.

Kata Kunci: Sampah, Pengolahan, Lingkungan, Edukasi
\end{abstract}

\begin{tabular}{|ll}
\hline cC) (;) (8) & $\begin{array}{l}\text { This work is licensed under a Creative Commons Attribution-NonCommercial 4.0 } \\
\text { International License }\end{array}$ \\
\hline
\end{tabular}

\section{Pendahuluan}

Pengelolaan sampah menjadi salah satu permasalahan lingkungan memberikan dampak negatif seperti pemanasan global dan kenyamanan masyarakat (Arifin, 2019; Wahyudi, 2019; Nindita, 2019; Suryawan et al., 2021). Sampah sebagai penyumbang emisi karbon juga berasal dari berbagai sektor kegiatan manusia, termasuk dari sektor pendidikan seperti halnya di Universitas Pertamina (Ridhosari dan Rahman, 2020). Tingginya timbulan sampah dapat dikarenakan kurangnya edukasi dan kepedulian masyarakat tentang pengelolaan sampah dan pengolahan sampah (Athaillah dan Husin, 2021; Apriyani dan Rahmaniati, 2018; Kahfi, 2017; Ulhasanah dan Goto, 2018). Padahal sampah dapat menjadi potensi yang menguntungkan apabila dimanfaatkan dengan baik.

Himpunan Mahasiswa Teknik Lingkungan Universitas Pertamina berinisiatif memulai aksi untuk mengelola dan mengolah sampah di lingkungan Universitas Pertamina agar memiliki nilai guna, khususnya sampah sisa makanan dan sampah botol plastik yang berasal dari aktivitas kantin kampus Universitas Pertamina. Dalam rangka mewujudkan aksi tersebut,Himpunan Mahasiswa Teknik Lingkungan Universitas Pertamina menyelenggarakan acara ini sebagai salah satu bentuk pengabdian masyarakat melalui edukasi pengelolaan dan pengolahan sampah, khususnya terhadap warga 
Kompleks Universitas Pertamina agar dapat berperan dalam memerangi isu sampah di Indonesia. Acara yang diselenggarakan bertajuk UPSTRACT 3.0 (Universitas Pertamina Starting Act 3.0) dengan tema Solid Waste Treatment for Sustainable Cities and Communities. UPSTRACT 3.0 berisi rangkaian kegiatan yang bertujuan untuk memupuk kepedulian terutama warga Kampus Universitas Pertamina terhadap sampah, seperti perlombaan inovasi tentang pemanfaatan sampah dan talkshow tentang pengolahan sampah.

\section{Metode}

Bentuk kegiatan dari UPSTRACT 3.0 adalah perlombaan inovasi teknologi, pemaparan mesin pencacah plastik, pemaparan redesain Tempat Pembuangan Semenrara (TPS) Universitas Pertamina, Talkshow Pengolahan Sampah, dan festival musik. Acara UPSTRACT 3.0 bertemakan pengolahan sampah dengan tagline "Waste Wisely, Save The Future". Lokasi pelaksanaan kegiatan ini adalah di Wilayah Komplek Universitas Pertamina, Jl Teuku Nyak Arief Simprug, Jakarta. Kegiatan UPSTRACT 3.0 diselenggarakan dengan sasaran utama yaitu warga kampus Universitas Pertamina khususnya mahasiswa/i Universitas Pertamina dan penjual makanan di kantin Universitas Pertamina serta siswa/i di wilayah DKI Jakarta. Rangkaian kegiatan UPSTRACT 3.0 dilaksanakan pada waktu dan tempat seperti pada Tabel 1.

Tabel 1. Rangkaian kegiatan UPSTRACT 3.0

\begin{tabular}{cll} 
No & \multicolumn{1}{c}{ Kegiatan } & \multicolumn{1}{c}{ Waktu/ Tempat } \\
\hline 1 & $\begin{array}{l}\text { Pemaparan tata cara penggunaan dan penerapan } \\
\text { mesin pencacah plastik dan pemaparan redesain TPS }\end{array}$ & Sabtu, 15 Februari 2020 \\
& & GOR ABC Pertamina \\
& & Simprug \\
\hline 2 & Edukasi melalui talkshow pengolahan sampah & GOR ABC Pertamina \\
& & Simprug \\
& & \\
\hline
\end{tabular}

\section{Hasil dan Pembahasan}

\subsection{Pemaparan Penggunaan Mesin Pencacah Plastik}

Pertimbangan dilakukannya kegiatan ini adalah agar warga Universitas Pertamina khususnya mahasiswa dan pedagang makanan di kantin mengetahui bahwa Universitas Pertamina melalui UPSTRACT 3.0 telah memiliki fasilitas untuk mengolahan sampah plastik, sehingga nantinya diharapkan warga Universitas Pertamina dapat turut andil dalam pengelolaan dan pengolahan sampah, misalnya dengan memilah sampah plastik dari jenis sampah-sampah yang lain. Adanya fasilitas pencacahan sampah plastik ini nantinya diharapkan dapat memberikan pengolahan sampah dan ekonomi yang berkelanjutan. Biji plastik yang dicacah dapat diproduksi dari penyulingan minyak mentah, harga biji plastik berfluktuasi mengikuti harga minyak mentah di pasar dunia (Nowneow, \& Rungreunganun, 2018). Harga biji plastik di Indonesia dapat mencapai Rp $8.500 / \mathrm{kg}$ (Astuti et al., 2020). Diperlukan perencanaan lebih lanjut untuk proses pencacahan, penjualan produk, dan pemanfaatan lebih lanjut agar inovasi teknologi yang diberikan dapat berkelanjutan. 


\subsection{Pemaparan Redesain TPS}

Redesain TPS dilakukan dengan tujuan agar sampah dapat dipilah dengan baik. Harapannya sampah yang telah dipilah sebelumnya dapat dikumpulkan pada TPS, sehingga dapat diidentifikasi bentuk pengolahan yang tepat. Kegiatan memilah sampah juga memiliki tujuan untuk mengidentifikasi sampah-sampah yang masih bernilai ekonomis. TPS yang dimiliki saat ini masih belum memanfaatkan peluang ekonomi dari sampah. Beberapa kampus di Indonesia telah merencanakan Material Recovery Facilities (MRF) dalam rangka mereduksi timbulan sampah seperti PPNS Surabaya dan UNAIR Kampus C (Setiani \& Ashari, 2018; Citrasari et al., 2019). Mendukung pengelolaan sampah yang baik dan mempermudah proses pemilahan sampah terutama sampah pet bottle yang akan dicacah. Gambaran desain ulang dari TPS yang direncanakan dapat dilihat pada Gambar 1 dan Gambar 2.

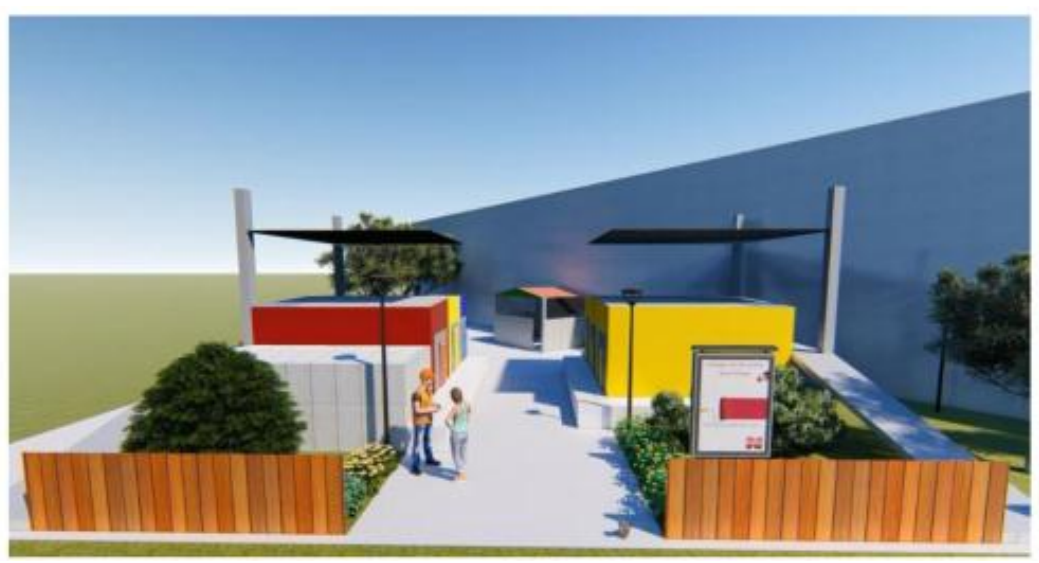

Gambar 1. Desain Tampak Atas Area TPS

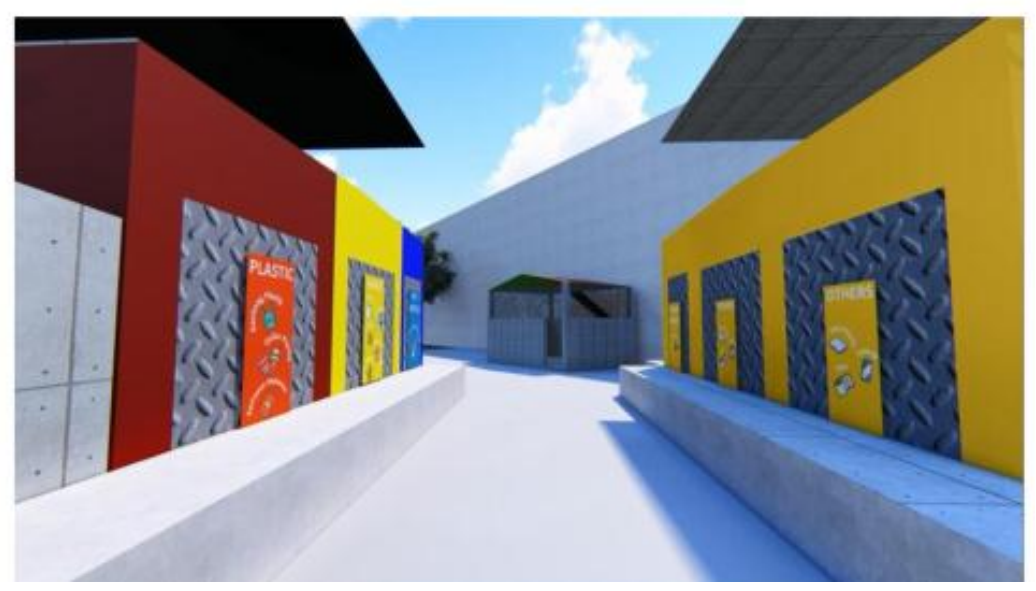

Gambar 2. Desain Bak/ Kontainer Tetap Sampah di TPS 


\subsection{Edukasi Melalui Talkshow Pengolahan Sampah}

Kegiatan berlangsung bersamaan dengan acara puncak UPSTRACT 3.0 pada Sabtu, 15 Februari 2020. Talkshow menghadirkan Ibu Nada Arini dari Sustainable Indonesia sebagai pembicara dan Dhea Umi Falentina dari Program Studi Teknik Lingkungan sebagai moderator. Ada 70 peserta yang hadir pada talkshow yang berasal dari beberapa program studi seperti Program Studi Manajemen, Program Studi Teknik Sipil, Program Studi Kimia, Program Studi Teknik Elektro, Program Studi Teknik Geofisika, dan Program Studi Teknik Lingkungan. Selain peserta dari mahasiswa, adapun tamu undangan yang hadir yaitu 4 dosen Teknik Lingkungan, 10 ketua himpunan Universitas Pertamina dan 7 orang perwakilan dari kios-kios kantin. Acara talkshow dapat disajikan pada Gambar 3.

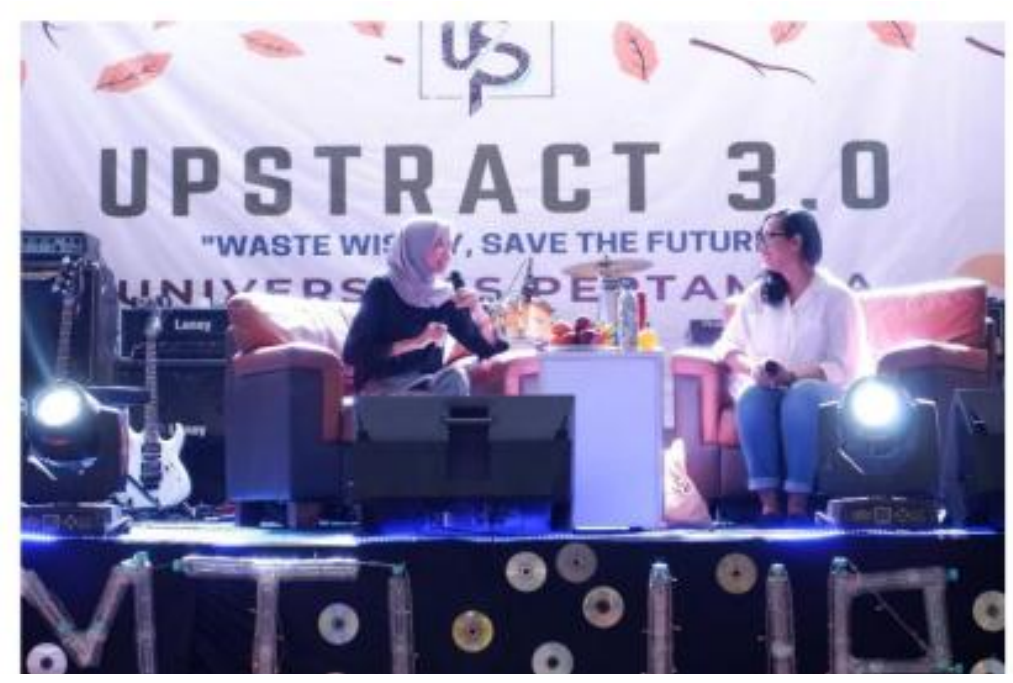

Gambar 3. Talkshow Pengolahan Sampah

Pelatihan pengenalan alat hasil inovasi kepada warga kampus Universitas Pertamina dan lingkungan sekitarnya dilkukan untuk memberikan informasi mengenai pentingnya pengelolaan dan pengolahan sampah dilakukan melalui kegiatan lomba inovasi teknologi INVIROLOGY dan talkshow Pengolahan sampah (Gambar 3). Kegiatan ini mengajak warga kampus Universitas Pertamina untuk dapat mempraktikkan pengelolaan dan pengolahan sampah melalui pemilahan jenis sampah terutama sampah plastik dan pembuatan kompos dari sampah organik khususnya di dalam lingkungan Universitas Pertamina. Pada acara ini, panitia penyelanggara UPSTRACT 3.0 menyediakan beberapa tempat sampah tambahan khusus untuk memilah sampah pet bottle sehingga praktik pemilahan sampah plastik dapat dilaksanakan dengan baik. Namun, untuk praktik pembuatan kompos dari sampah organik pada akhirnya tidak dapat terlaksana karena adanya keterbatasan finansial dalam pelaksanaan sehingga praktik lebih difokuskan pada sampah plastik.

Warga kampus juga dapat mereduksi sampah yang dihasilkan kampus Universitas Pertamina dengan cara komposting dan pencacahan ke TPA ataupun ke landfill. Pada akhirnya pengurangan output sampah yang dihasilkan kampus Universitas Pertamina hanya dengan cara pencacahan sampah plastik khususnya pet bottle karena tidak dimungkinkan untuk dilaksanakan kegiatan composting karena keterbatasan finansial untuk membeli composter. Membangun kebudayaan peduli 
sampah oleh seluruh warga kampus Universitas Pertamina (mahasiswa, dosen, staff, dan pihak-pihak yang berada dalam satu kompleks Universitas Pertamina termasuk Pertamina Foundation, Pertamina Simprug Residence, dan lain-lain). Kebudayaan peduli sampah ini dipupuk melalui pemilahan sampah pet bottle agar dapat dicacah lalu dimanfaatkan kembali dan melalui talkshow. Sampah pet bottle yang belum dicacah hanya dihargai Rp. 400/kg dan jika dicacah menjadi biji plastik harga material tersebut menjadi lebih tinggi (Fitriyano, 2017) atau sekitar Rp. 8.000/kg (Wijayanto \& Rusdi, 2017).

\section{Kesimpulan}

Tingginya antusias warga kampus terhadap kegiatan ini menunjukkan kepedulian warga kampus terhadap lingkungan terutama pengelolaan sampahan. Inovasi lingkungan yang diberikan peserta juga menunjukkan warga kampus mampu mengolah sampah dengan baik. Kepedulian tentang pengolahan sampah juga terlihat dari perencanaan yang matang terhadap TPS dan adanya support alat pecacah sampah pet bottle yang mampu mereduksi timbulan sampah serta secara tidak langsung nantinya bermanfaat secara ekonomi. Kegitan UPSTRACT seterusnya akan dilakukan untuk peningkatan kualitas lingkungan dan berkelanjutan dengan mempertimbangkan aspek lain seperti ekonomi, social, dan budaya dalam lingkup kampus Universitas Pertamina.

\section{Acknowledgement}

Terima kasih kepada Bapak/Ibu mitra kegitan ini seperti petugas kebersihan dan pedagang kantin di kompleks Universitas Pertamina. Penulis juga berterima kasih kepada sponsor yang telah membantu terjalinnya acara ini hingga selesai.

\section{Daftar Pustaka}

Arifin, M. Z. (2019). Prospek Inovasi Pengelolaan Sampah Sebagai Strategi Mitigasi Pemanasan Global di Kota Magelang. Jendela Inovasi Daerah, 2(2), 13-31.

Apriyani, N., \& Rahmaniati, R. (2018). Pendampingan Siswa dan Masyarakat dalam Bidang Pendidikan, Keterampilan, Ekstrakurikuler dan Kepedulian terhadap Lingkungan. PengabdianMu: Jurnal Ilmiah Pengabdian Kepada Masyarakat, 3(2), 152-159.

Astuti, A. D., Wahyudi, J., Ernawati, A., \& Aini, S. Q. (2020). Kajian Pendirian Usaha Biji Plastik di Kabupaten Pati, Jawa Tengah. Jurnal Litbang: Media Informasi Penelitian, Pengembangan dan IPTEK, 16(2), 95-112.

Athaillah, T., \& Husin, H. (2021). Edukasi Pemanfaatan Limbah Sisa Makanan Menjadi Produk Yang Bernilai Ekonomis. Dinamisia: Jurnal Pengabdian Kepada Masyarakat, 5(2), 437-442.

Citrasari, N., Sitogasa, P. S. A., Burhan, A. L., \& Sari, N. K. (2019, March). The design of Material Recovery Facilities (MRF)-based Temporary Disposal Site (TDS) at Universitas Airlangga campus C. In IOP Conference Series: Earth and Environmental Science (Vol. 245, No. 1, p. 012010). IOP Publishing.

Fitriyano, G. (2018). Pengaruh Suhu Proses Cetak Terhadap Kekuatan Panel Backsplash Dari Pemanfaatan Botol Pet Bekas. Jurnal Integrasi Proses, 7(2), 49-56. 
Juairiyah, O., Novriadhy, D., \& Hatta, H. (2020, December). Inovasi Siswa SMA/SMK untuk Memecahkan Isu Pangan, Energi dan Lingkungan di Provinsi Sumatera Selatan. In Seminar Nasional Lahan Suboptimal (No. 1).

Kahfi, A. (2017). Tinjauan terhadap pengelolaan sampah. Jurisprudentie: Jurusan Ilmu Hukum Fakultas Syariah dan Hukum, 4(1), 12-25.

Nindita, V. (2019). Estimasi Emisi (N2O) Dari Timbulan Sampah Di Kampus 3 UPGRIS Semarang. Bangun Rekaprima: Majalah Ilmiah Pengembangan Rekayasa, Sosial dan Humaniora, 5(2, Oktober), 1-8.

Nowneow, A., \& Rungreunganun, V. (2018). Poly Vinyl Chloride Pellet Price Forecasting Using Arima Model. International Journal of Mechanical Engineering and Technology (IJMET), 8(13), 224-232.

Ridhosari, B., \& Rahman, A. (2020). Carbon footprint assessment at Universitas Pertamina from the scope of electricity, transportation, and waste generation: toward a green campus and promotion of environmental sustainability. Journal of Cleaner Production, 246, 119172.

Setiani, V., \& Ashari, M. L. (2018, December). Perencanaan Material Recovery Facility (MRF) limbah padat non B3 di PPNS. In Seminar MASTER PPNS (Vol. 3, No. 1, pp. 155-158).

Suryawan, I. W. K., Rahman, A., Septiariva, I. Y., Suhardono, S., \& Wijaya, I. M. W. (2021). Life Cycle Assessment of Solid Waste Generation During And Before Pandemic Of Covid-19 In Bali Province. Journal of Sustainability Science and Management, 16(1), 11-21.

Ulhasanah, N., \& Goto, N. (2018). Assessment of citizens' environmental behavior toward municipal solid waste management for a better and appropriate system in Indonesia: a case study of Padang City. Journal of Material Cycles and Waste Management, 20(2), 1257-1272.

Wahyudi, J. (2019). Emisi Gas Rumah Kaca (GRK) dari Pembakaran Terbuka Sampah Rumah Tangga Menggunakan Model IPCC. Jurnal Litbang: Media Informasi Penelitian, Pengembangan dan IPTEK, 15(1), 65-76.

Wijayanto, A., \& Rusdi, R. (2017). Pendampingan Kelompok Usaha Pencacahan Limbah Plastik Di Kabupaten Malang. JPM PAMBUDI, 1(1), 11-11. 